\title{
Mechanical and tribological properties of epoxy matrix composites modified with microencapsulated mixture of wax lubricant and multi-walled carbon nanotubes
}

\author{
Nay Win KHUN, He ZHANG, Jinglei YANG*', Erjia LIU* \\ School of Mechanical and Aerospace Engineering, Nanyang Technological University, 50 Nanyang Avenue, Singapore 639798, Singapore \\ Received: 19 June 2013 / Revised: 01 August 2013 / Accepted: 09 October 2013 \\ (C) The author(s) 2013. This article is published with open access at Springerlink.com
}

\begin{abstract}
The mechanical and tribological properties of epoxy composites modified with microencapsulated wax lubricant and multi-walled carbon nanotubes (MWCNTs) were investigated. The increased soft microcapsules embedded in the epoxy matrices were responsible for the reduced micro-hardness and Young's modulus of the epoxy composites. It was found that the friction of the epoxy composites greatly decreased with increased microcapsule content due to combined lubricating effects of the both wax lubricant and MWCNTs. As a result, the wear of the epoxy composites apparently decreased with increased microcapsule content.
\end{abstract}

Keywords: epoxy composite; microcapsule; wax lubricant; MWCNT; tribology

\section{Introduction}

Fibre reinforcements and solid or liquid lubricants are frequently applied to improve the wear resistance of polymers. Fibre reinforcements, such as carbon and glass fibres, in polymer matrices enhance the wear resistance of the polymer composites (PCs) by improving their mechanical strength [1-4]. Solid lubricants, such as graphite and polytetrafluoroethylene (PTFE), reduce the wear of PCs by developing a transfer film between two rubbing surfaces [5-7]. However, solid additives cannot always give desired tribological properties of PCs. Wang and co-workers [8] reported that the use of liquid paraffin during tribological test improved the wear resistance of epoxy composites by reducing the friction of the composites. Although a liquid lubricant can improve the tribological performance of polymers, a degradation of materials caused by absorption and osmosis of the lubricant into them may limit the application of materials [8, 9]. Guo et al. [10] reported that incorporation of

* Corresponding author: Jinglei YANG, Erjia LIU.

E-mail: MJLYang@ntu.edu.sg; MEJLiu@ntu.edu.sg microencapsulated lubricant in epoxy matrices could overcome the above mentioned problems because the sustainably released lubricant from broken microcapsules during sliding lubricated rubbing surfaces. Recently, Khun et al. [11] reported that silicone composite coatings modified with microencapsulated wax lubricant exhibited significantly lower friction coefficients compared to pure silicone coatings. Though the friction coefficient of epoxy composites apparently decreases with increased microcapsule content, the mechanical strength of the composites significantly decreases due to the increased content of soft microcapsules in the hard epoxy matrices [10]. Therefore, it is a great challenge to keep the low friction of epoxy composites when a small amount of microcapsules is introduced into the composites. It is reported that carbon fillers, such as carbon nanotubes (CNTs), in polymer matrices can reduce the friction of the PCs via their solid lubricating and free-rolling effects [12-19]. It is therefore expected that incorporation of wax lubricant mixed with carbon fillers in microcapsules would improve the tribological performance of PCs. An understanding of a correlation between the microcapsule content in epoxy composites and 
their tribological properties is essential for successful tribological applications.

In this study, a wax lubricant mixed with multiwalled carbon nanotubes (MWCNTs) was microencapsulated through in-situ polymerization. The synthesized microcapsules were incorporated in epoxy matrix to form a new type of epoxy based composite. The microcapsule content was varied from 0.5 to $5 \mathrm{wt} \%$ to investigate the tribological properties of the epoxy composites with respect to microcapsule content.

\section{Experimental details}

\subsection{Materials}

The urea $\left(\mathrm{CO}\left(\mathrm{NH}_{2}\right)_{2}\right)$, formaldehyde $\left(\mathrm{CH}_{2} \mathrm{O}, \mathrm{PUF}\right)$, ammonium chloride $\left(\mathrm{NH}_{4} \mathrm{Cl}\right)$, and sodium hydroxide $(\mathrm{NaOH})$ were purchased from Sigma-Aldrich. The surfactant, ethylene maleic anhydride copolymer (EMA), was purchased from MP Biomedicals. The MWCNTs were supplied by Chengdu Organic Chemicals Co., Ltd. The diameter, length, number of walls, and bulk density of the MWCNTs according to the manufacturer's specifications were $5-20 \mathrm{~nm}$, 1-10 $\mu \mathrm{m}, 3-15$, and $140-230 \mathrm{~kg} \cdot \mathrm{m}^{-3}$, respectively. The wax lubricant (Episol B2531, C14-C20) was ordered from EP chem. International Pte. Ltd. Epoxy resin (Epocote 1008 Part A) and hardener (Part B) both were ordered from Shell AG.

The $1 \mathrm{wt} \%$ MWCNTs were dispersed into the wax lubricant by a two-step method: Sonication (Misonix, Model: Sonicator 3000) in an ice-bath under power 30 watts for $10 \mathrm{~min}$ followed by homogenization (Ika, Model: T18 basic Ultra-Turrax) for another $10 \mathrm{~min}$ at 10,000 rpm. Microcapsules were prepared by in-situ polymerization in an oil-in-water emulsion [20]. Under room temperature (RT) (about $22-24{ }^{\circ} \mathrm{C}$ ), $50 \mathrm{~mL}$ deionized (DI) water, $1.25 \mathrm{~g}$ urea, $0.125 \mathrm{~g} \mathrm{NH}_{4} \mathrm{Cl}$, $0.125 \mathrm{~g}$ resorcinol $\left(\mathrm{C}_{6} \mathrm{H}_{6} \mathrm{O}_{2}\right)$ and $12.5 \mathrm{~mL}$ of an aqueous solution containing $2.5 \mathrm{wt} \%$ ethylene maleic anhydride copolymer (EMA) were added into a $250 \mathrm{~mL}$ beaker placed in a temperature-controlled water-bath. The $\mathrm{pH}$ of the mixture was adjusted to 3.5 by adding $\mathrm{NaOH}$. After that, $15 \mathrm{~mL}$ of the MWCNT dispersed wax lubricant was slowly poured into the mixture. When the mixture was emulsified for $10 \mathrm{~min}$ at a stirring rate of $500 \mathrm{rpm}$ (Caframo, Model: BDC6015), $3.17 \mathrm{~g}$ of an aqueous solution containing $37 \mathrm{wt} \%$ formaldehyde was dropped into the emulsion. After the final mixture was heated to $55^{\circ} \mathrm{C}$ at a heating rate of $35^{\circ} \mathrm{C} / \mathrm{h}$ and agitated for $4 \mathrm{~h}$, the microencapsulation process was stopped. The microcapsules were separated under vacuum with a coarse-fritted filter, which were then rinsed with DI water and dried for $24 \mathrm{~h}$ at RT.

Epoxy resin and hardener were mixed with a weight ratio of 3:1. The epoxy and composites with different microcapsule contents from 0.5 to $5 \mathrm{wt} \%$ were moulded and fully cured at RT.

\subsection{Characterization}

The root-mean-square surface roughnesses $\left(R_{\mathrm{q}}\right)$ of the samples were measured using surface profilometry (Talyscan 150) with a diamond stylus of $4 \mu \mathrm{m}$ in diameter in a scan size of $2 \mathrm{~mm} \times 2 \mathrm{~mm}$. Five measurements on each sample were carried out to get an average $R_{\mathrm{q}}$ value.

The surface morphology of the samples was studied using scanning electron microscopy (SEM, JEOLJSM-5600LV).

The hardnesses and Young's moduli of the samples were measured using a microindenter (MHT, CSM) with a pyramidal shaped diamond tip of $20 \mu \mathrm{m}$ in diameter. The indentation test was performed in a load control mode with a total load of $3 \mathrm{~N}$. In each indentation test, the loading and unloading rates and dwelling time at the peak load were $6 \mathrm{~N} / \mathrm{min}, 6 \mathrm{~N} / \mathrm{min}$ and $5 \mathrm{~s}$, respectively. The hardness and Young's modulus of the samples were derived using Oliver \& Pharr's method and average values were taken from eight indentation measurements carried out at different locations on each sample [21].

The tribological properties of the samples were investigated using a ball-on-disc microtribometer (CSM) operated in rotary mode at RT. Three tests were conducted on each sample to get average tribological results. In a test, a steel ball (Cr6) of $6 \mathrm{~mm}$ in diameter was rotated on a sample in a circular path of $2 \mathrm{~mm}$ in radius for about 20,000 laps at a sliding speed of $2 \mathrm{~cm} / \mathrm{s}$ under a normal load of $2 \mathrm{~N}$. The wear tracks on the samples were then measured using white light confocal imaging profilometry (Nikon L150). 


\section{Results and discussion}

Figure 1(a) shows the SEM micrograph of the microcapsules containing wax lubricant and MWCNTs, in which the sizes of the microcapsules range from about 150 to $300 \mu \mathrm{m}$ in diameter. As shown in Fig. 1(b), the cotton-like features observed on the rough surface of the microcapsule result from the dangling MWCNTs in the shell wall and the precipitation of ureaformaldehyde (UF) nanoparticles [20]. In Fig. 1(c), the SEM micrograph of an artificially crushed microcapsule clearly indicates a core-shell structure of the microcapsule [22]. The MWCNTs are evidently found and fairly dispersed on the interior surface of the microcapsule with some agglomeration, as shown in Fig. 1(d).

Figure 2 presents the surface topographies of the epoxy and epoxy composite with $5 \mathrm{wt} \%$ microcapsules. In Fig. 2(a), pin holes can be clearly seen on the surface of the epoxy, which may result from degassing or rapid curing of the epoxy. However, the apparently lessened formation of the pin holes on the surface of the epoxy composite with the incorporation of $5 \mathrm{wt} \%$ microcapsules, as shown in Fig. 2(b), indicates the improved uniformity of the epoxy composite. Although the slightly protruded microcapsules above the surface of the epoxy composite ( $5 \mathrm{wt} \%$ microcapsules) are found in Fig. 2(b), its lower $R_{\mathrm{q}}$ value $(\sim 1.9 \mu \mathrm{m})$ than that $(\sim 3.1 \mu \mathrm{m})$ of the epoxy is mainly attributed to the suppression of the pin holes on the surface of the composite.

Figure 3 shows the hardnesses and Young's moduli of the epoxy and composites with different microcapsule contents. The hardness and Young's modulus of the epoxy matrix are about $198.5 \mathrm{MPa}$ and $3.4 \mathrm{GPa}$, respectively. However, the increased content of microcapsules in the epoxy composites from 0.5 to $5 \mathrm{wt} \%$ decreases the hardness and Young's modulus of the composites from about $177.8 \mathrm{MPa}$ and $2.2 \mathrm{GPa}$ to about $113 \mathrm{MPa}$ and $1.5 \mathrm{GPa}$, respectively, which is a direct consequence of the lower hardness and elastic modulus of the microcapsules with respect to those of the epoxy matrix [23, 24].

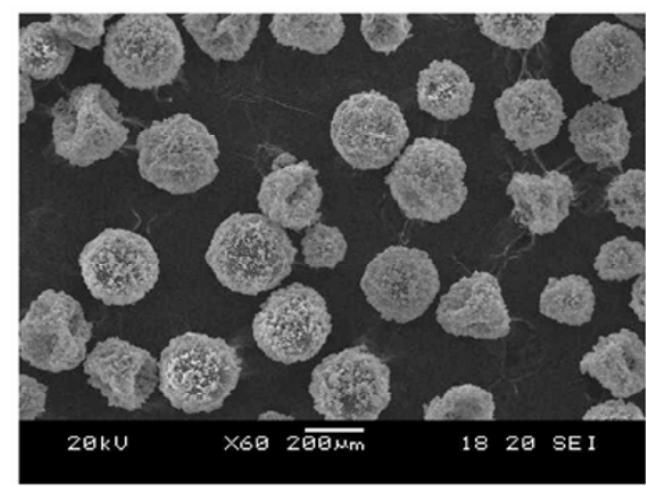

(a)

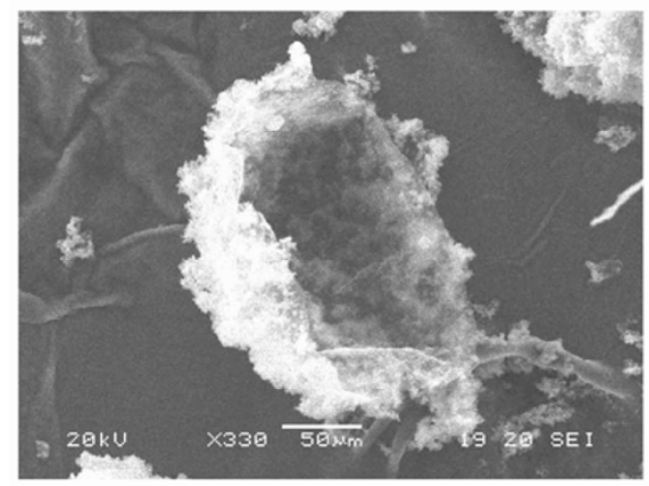

(c)

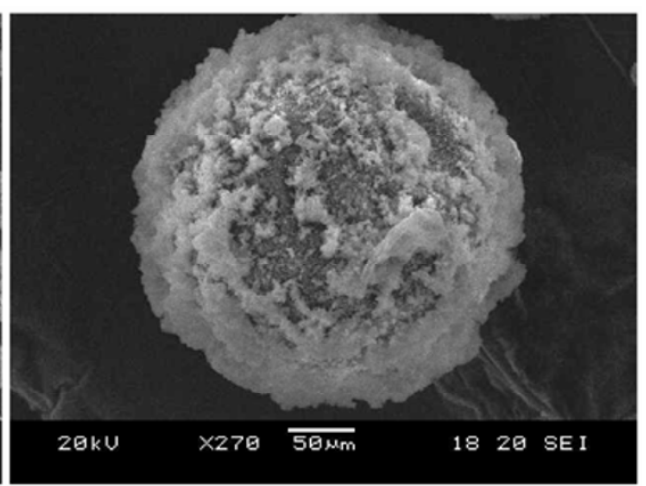

(b)

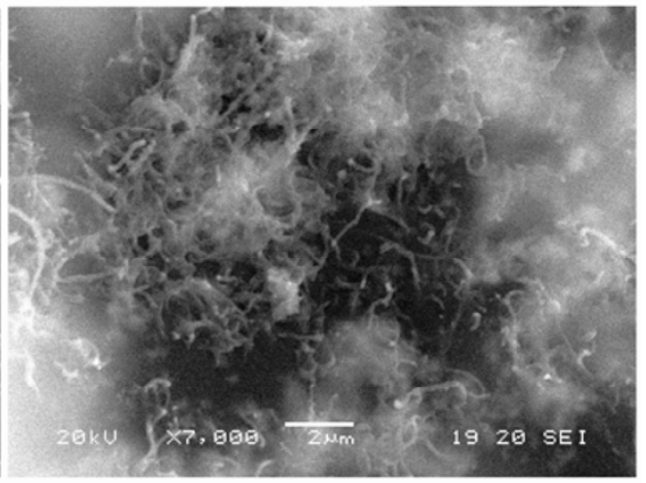

(d)

Fig. 1 SEM micrographs of (a) microcapsules containing wax lubricant and MWCNTs, (b) an enlarged view of a microcapsule, (c) a crushed microcapsule, and (d) an interior surface of a crushed microcapsule. 


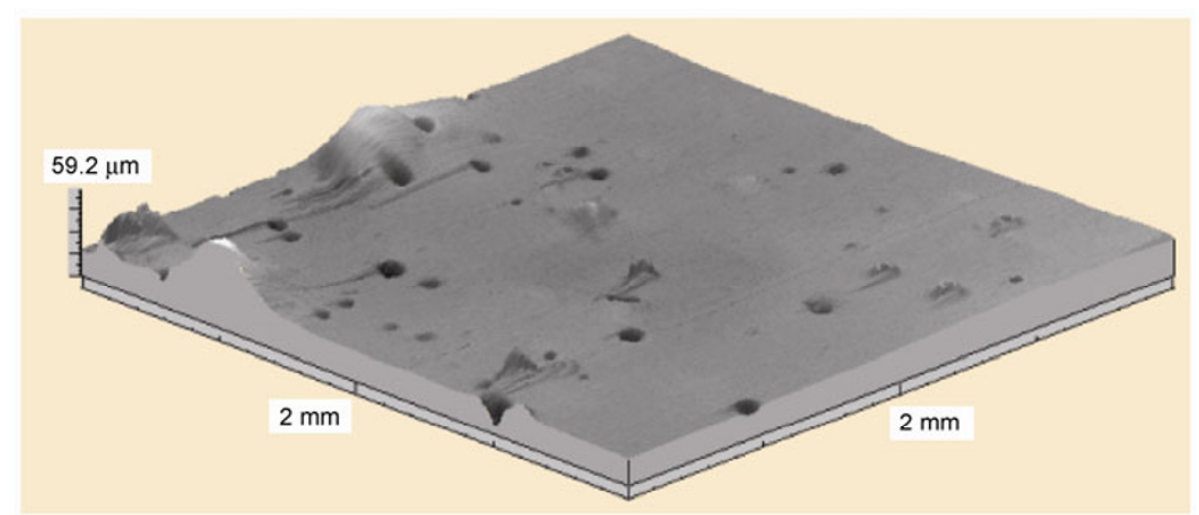

(a)

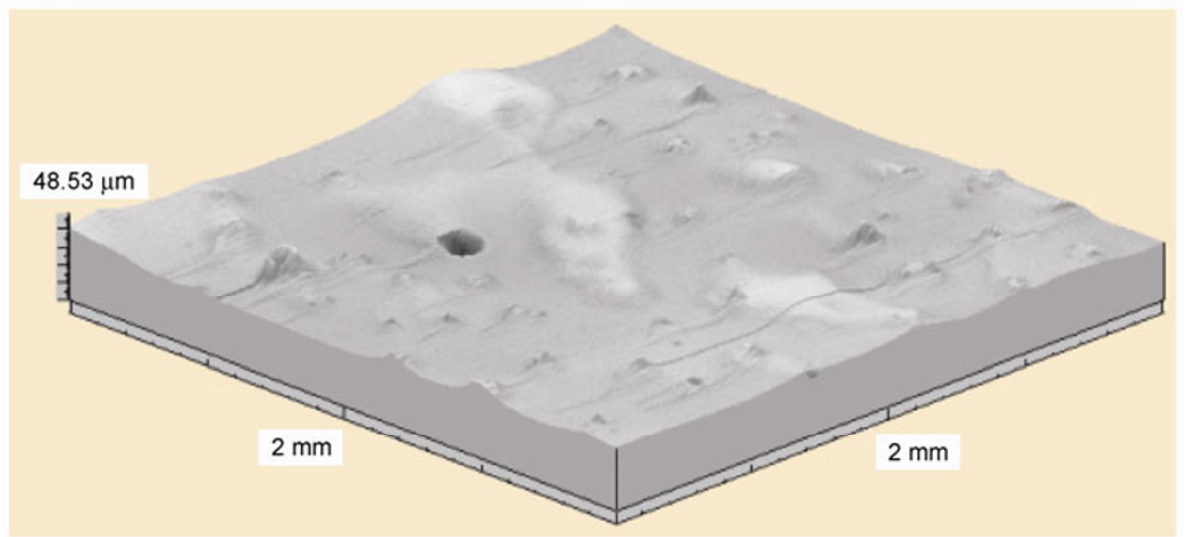

(b)

Fig. 2 Surface topographies of (a) epoxy and (b) epoxy composite with $5 \mathrm{wt} \%$ microcapsules measured using surface profilometry.

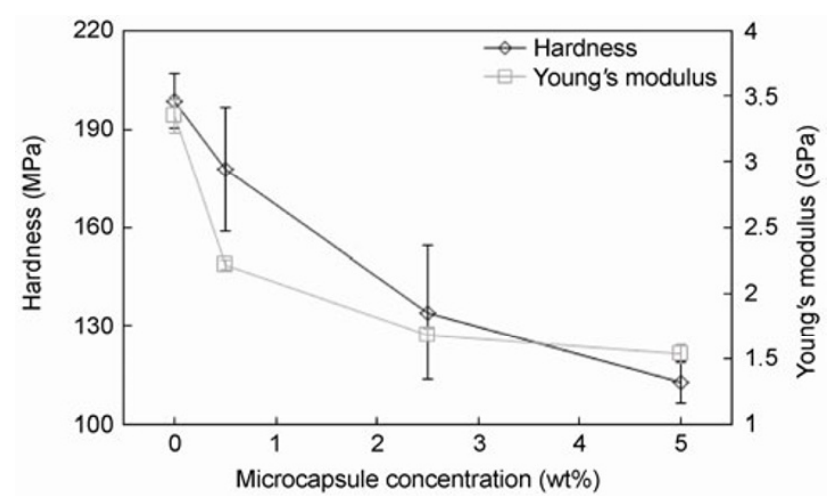

Fig. 3 Hardnesses and Young's moduli of epoxy composites as a function of microcapsule content.

The tribological properties of the epoxy and epoxy composites with different microcapsule contents were investigated by sliding against the $6 \mathrm{~mm} \mathrm{Cr} 6$ steel balls for about 20,000 laps under a normal load of $2 \mathrm{~N}$. Figure 4(a) shows the friction coefficients of the epoxy and epoxy composites as a function of the number of laps. The friction coefficient of the epoxy dramatically increases to about 0.63 after 2,400 laps, becomes stable up to 10,000 laps and then further slightly increases with increased laps till 20,000 laps. In the running-in period, the increased wear of the rubbing surfaces increases the friction coefficient of the epoxy by promoting a contact area between the steel ball and epoxy. Furthermore, the prolonged rubbing of the steel ball on the epoxy detaches wear debris from the epoxy surface so that the existence of irregular shaped wear debris at the polymer/metal interface as third bodies gives rise to the higher friction than the initial friction via third body abrasive wear [25]. As a result, the friction coefficient of the epoxy further increases with increased laps after 10,000 as shown in Fig. 4(a). However, the incorporation of $0.5 \mathrm{wt} \%$ microcapsules greatly lowers the friction coefficient of the epoxy composite throughout the wear test although the increased friction coefficient with increased laps is still observed in the running-in period. During the sliding, the released lubricant from broken microcapsules effectively lubricates the rubbing surfaces, lessens the direct solid-solid contact between the steel ball and 
composite, reduces the wear of the rubbing surfaces, and lessens the interactions between the rubbing surfaces and wear particles. In addition, the MWCNTs incorporated in the embedded microcapsules in the epoxy composite can be released during the wear of the composite and transferred to the interface between the steel ball and composite. Thus, the MWCNTs released serve as a solid lubricant to reduce the friction of the composite [15-19]. Moreover, the MWCNTs on the surface can not only serve as spacers to prevent the direct contact between the steel ball and composite but also slide or roll between the rubbing surfaces [26]. Therefore, the combined lubricating effects of the both wax lubricant and MWCNTs greatly reduce the friction of the epoxy composite even with only $0.5 \mathrm{wt} \%$ microcapsules. The increased microcapsule content in the epoxy composite through $5 \mathrm{wt} \%$ significantly shortens the running-in period and results in the consistently lowered friction coefficient of the composites as shown in Fig. 4(a). Since a smoother surface can result in a lower friction, the reduced surface roughness of the epoxy composites with increased microcapsule content (Fig. 2) should be correlated to the decreased friction of the composites [27-31].

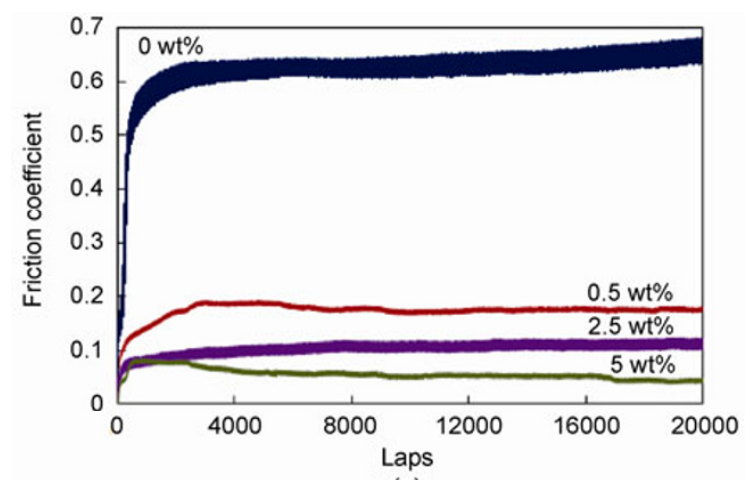

(a)

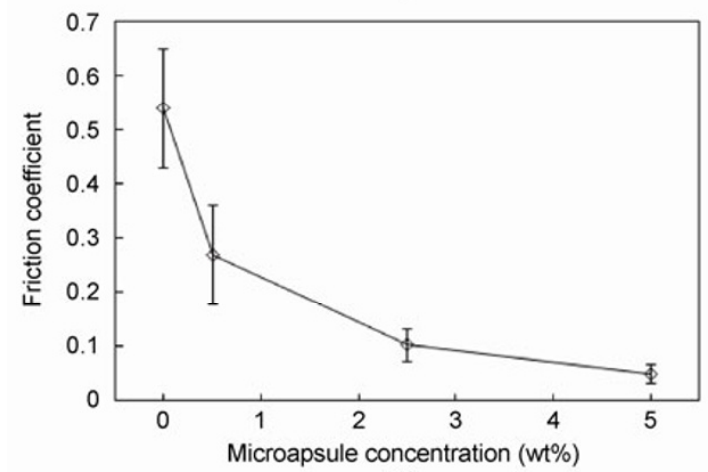

(b)

Fig. 4 Friction coefficients of epoxy composites as functions of (a) the number of laps and (b) microcapsule content.
Figure 4(b) shows that the mean friction coefficient of the epoxy composites significantly decreases from about 0.27 to 0.049 with increased microcapsule content from 0.5 to $5 \mathrm{wt} \%$ as the friction coefficients of the epoxy composites are apparently lower than that (about 0.54) of the epoxy. It is clear that the increased microcapsule content promotes the combined lubricating effects of the wax lubricant and MWCNTs and the free-rolling effect of the MWCTNs. Therefore, the microcapsule incorporated epoxy composites exhibit the much lower friction than the epoxy as the higher microcapsule content gives rise to the lower friction of the epoxy composites. Guo et al. [10] reported that the incorporation of $10 \mathrm{wt} \%$ microcapsules containing lubricant oil in an epoxy matrix could give the friction coefficient of about 0.14 measured using a block-on-ring apparatus. In this study, the friction coefficient of the epoxy composite with $5 \mathrm{wt} \%$ microcapsules containing both wax lubricant and MWCNTs measured using a ball-ondisc apparatus is about 0.049 , indicating that the co-incorporation of the wax lubricant and MWCNTs in the microcapsules would give rise to the better frictional performance of the composite.

Figure 5 shows the wear widths and depths of the epoxy and epoxy composites with different microcapsule contents. It is found that the wear width and depth of the epoxy are about $300.2 \mu \mathrm{m}$ and $2.1 \mu \mathrm{m}$, respectively. The incorporation of $0.5 \mathrm{wt} \%$ microcapsules in the epoxy matrix significantly decreases the wear width and depth of the composite to about $233.5 \mu \mathrm{m}$ and $1.6 \mu \mathrm{m}$, respectively. The wear width and depth of the epoxy composites further decrease from about $193.5 \mu \mathrm{m}$ and $0.9 \mu \mathrm{m}$ to about $68 \mu \mathrm{m}$ and

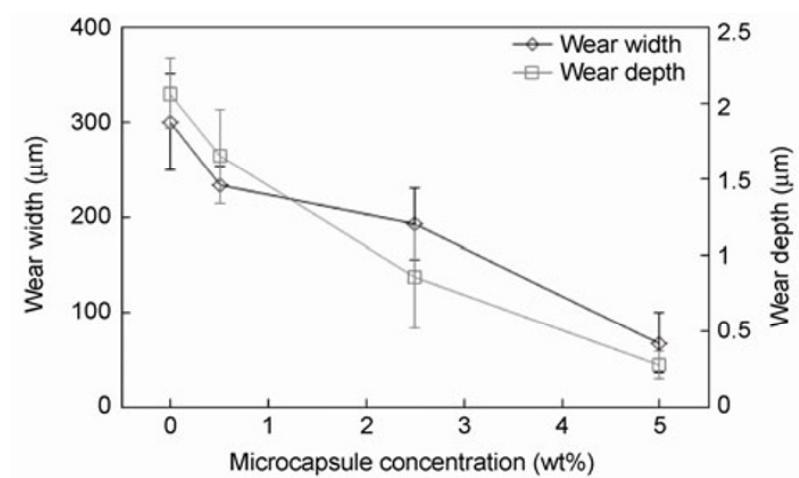

Fig. 5 Wear widths and depths of epoxy composites as a function of microcapsule content. 
$0.3 \mu \mathrm{m}$, respectively, with increased microcapsule content from 2.5 to $5 \mathrm{wt} \%$, indicating that the released lubricant effectively reduces the wear of the epoxy composites during the sliding.

Figure 6(a) shows the surface morphology of the worn epoxy after sliding against a steel ball for about 20,000 laps under a normal load of $2 \mathrm{~N}$. The wear track on the surface of the epoxy shows that the rubbing of the steel ball on the epoxy during the wear test generates the abrasive wear of the epoxy as shown in Fig. 6(a). The wear track looks like a fish backbone and some tiny cracks along the track can be found. The cross-points of the cracks are probably near the centre of the wear track and the cracks are convex with an angle of about $120^{\circ}$ to the sliding direction. This arises from repeated stress concentration occurred in front of the steel ball during the repeated sliding of the steel ball on the epoxy surface. In addition, the repeated sliding causes surface fatigue that in turn initiates minute cracks perpendicular to the sliding direction and propagates the cracks into the subsurface of the epoxy [32,33]. The formation of a network of micro-cracks creates micro-wave features that can be clearly seen in the centre of the wear track where the most severe wear of the epoxy surface occurs as shown in Fig. 6(b) [32, 33].

The incorporation of $5 \mathrm{wt} \%$ microcapsules in the epoxy greatly reduces the wear of the composite so the wear of the composite is not as severe as that of the epoxy, as shown in Fig. 6(c). In addition, micro-cracks and wave features are not apparently found on the surface of the epoxy composite with $5 \mathrm{wt} \%$ microcapsules because the self-lubricating of the composite surface effectively suppresses the surface fatigue wear. In Fig. 6(c), the surrounding areas of the broken microcapsules on the wear track of the epoxy composite are apparently contaminated by the released wax lubricant, which confirms that the wear of the composite surface during the sliding results in the breakage of the microcapsules and the subsequent release of the wax lubricant for self-lubricating.

Figure $6(\mathrm{~d})$ shows a view of a broken microcapsule on the wear track of the epoxy composite with $5 \mathrm{wt} \%$ microcapsules, from which it can be seen that the breakage of the microcapsule leaves a single hole on the surface. In addition, the debris produced by the

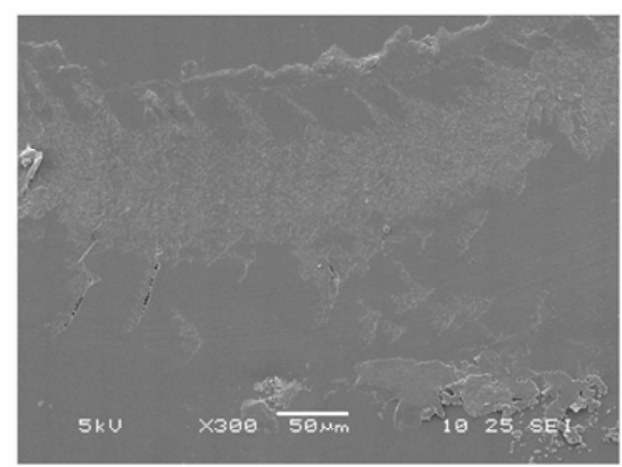

(a)

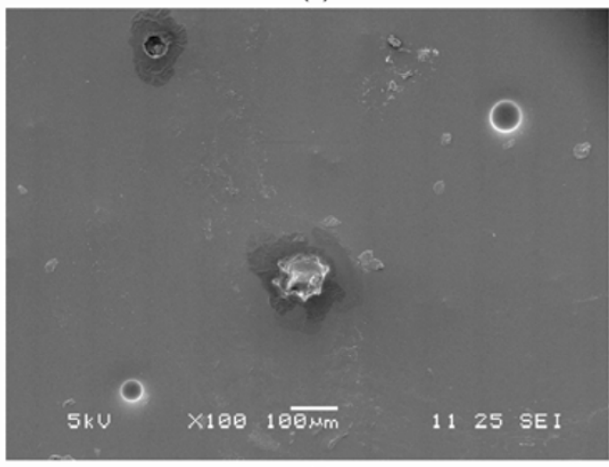

(c)

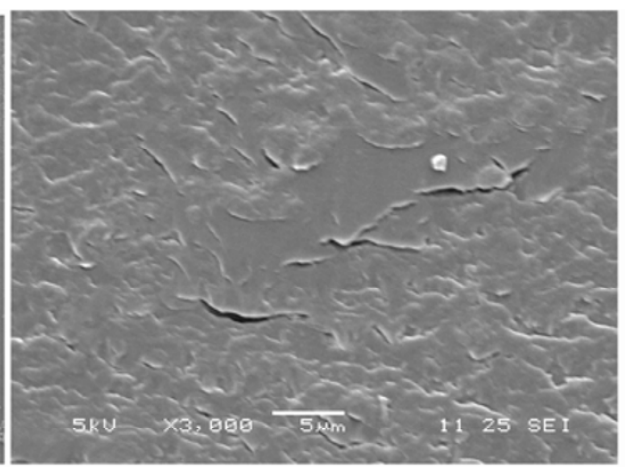

(b)

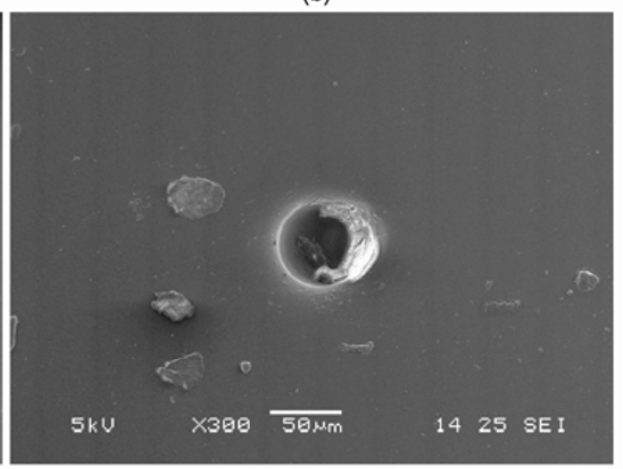

(d)

Fig. 6 SEM micrographs showing surface morphologies of worn (a and b) epoxy and (c and d) epoxy composite with 5 wt $\%$ microcapsules at different magnifications. 
breakage of the microcapsule are apparently found nearby. The debris can serve as spacers to prevent the direct contact between the steel ball and composite during the sliding as the MWCNTs contained in the debris can lubricate the rubbing surfaces. It can be deduced that the co-incorporation of the wax lubricant and MWCNTs in the embedded microcapsules in the epoxy composites greatly improves the tribological performance of the composites through their combined self-lubricating effects.

\section{Conclusions}

The mechanical and tribological properties of epoxy composites modified with microcapsules containing a mixture of a wax lubricant and MWCNTs were investigated with respect to microcapsule content. The incorporation of the soft microcapsules in the hard epoxy matrix was responsible for the reduced hardness and Young's modulus of the composites with increased microcapsule content. The friction coefficients of the epoxy composites were much lower than that of the epoxy and consistently decreased with increased microcapsule content as well, which was attributed to the combined self-lubricating effects of the wax lubricant and MWCNTs. The reduced friction of the epoxy composites consequently led to the lowered wear of the composites. The SEM observation confirmed that the wear of the composite surface during the wear test resulted in the breakage of microcapsules and the subsequent release of wax lubricant for lubricating the rubbing surfaces and preventing the direct solid-solid contact between the rubbing surfaces.

\section{Acknowledgement}

The authors would like to acknowledge the financial support from the Materials Innovation for Marine and Offshore (MIMO) program with the grant number of SERC1123004032 under the Agency for Science, Technology and Research (A*Star) of Singapore.

Open Access: This article is distributed under the terms of the Creative Commons Attribution License which permits any use, distribution, and reproduction in any medium, provided the original author(s) and source are credited.

\section{References}

[1] Bonfield W, Edwards B C, Markham A J, White J R. Wear transfer films formed by carbon fibre reinforced epoxy resin sliding on stainless steel. Wear 37: 113-121 (1976)

[2] Hokao M, Hironaka S, Suda Y, Yamamoto Y. Friction and wear properties of graphite/glassy carbon composites. Wear 237: 54-59 (2000)

[3] Khun N W, Liu E. Tribological behavior of polyurethane immersed in acid solution. Tribol Trans 55: 401-408 (2012)

[4] Khun N W, Liu E. Thermal, mechanical and tribological properties of polycarbonate/acrylonitrile-butadiene-styrene blends. J Poly Eng 33: 535-543 (2013)

[5] Bahadur S. The development of transfer layers and their role in polymer tribology. Wear 245: 92-99 (2000)

[6] Bahadur S, Polineni V K. Tribological studies of glass fabricreinforced polyamide composites filled with $\mathrm{CuO}$ and PTFE. Wear 200: 95-104 (1996)

[7] Cenna A A, Dastoor P, Beehag A, Page N W. Effects of graphite particle addition upon the abrasive wear of polymer surfaces. J Mater Sci 36: 891-900 (2001)

[8] Wan Y Z, Luo H L, Wang Y L, Huang Y, Li Q Y, Zhou F G. Friction and wear behavior of three-dimensional braided carbon fiber/epoxy composites under lubricated sliding conditions. J Mater Sci 40: 4475-4481 (2005)

[9] Zhang Z Z, Liu W M, Xue Q J. Effects of various kinds of fillers on the tribolgoical behavior of polytetrafluoroethylene composites under dry and oil-lubricated conditions. J Appl Polym Sci 80: 1891-1897 (2001)

[10] Guo Q B, Lau K T, Zheng B F, Rong M Z, Zhang M Q. Imparting ultra-low friction and wear rate to epoxy by the incorporation of microencapsulated lubricant? Macromol Mater Eng 294: 20-24 (2009)

[11] Khun N W, Zhang H, Yang J L, Liu E. Tribological performance of silicone composite coatings filled with waxcontaining microcapsules. Wear 296: 575-582 (2012)

[12] Calvert P. Nanotube composites: A recipe for strength. Nature 399: 210-211 (1999)

[13] Treacy M M J, Ebbesen T W, Gibson J M. Exceptionally high Young's modulus observed for individual carbon nanotubes. Nature 381: 678-680 (1996)

[14] Lee C J, Park J, Kang S Y, Lee J H. Growth and filed electron emission of vertically aligned multiwalled carbon nanotubes. Chem Phys Lett 326: 175-180 (2000)

[15] Chen W X, Li B, Han G, Wang L Y, Tu J P, Xu Z D. Tribological behavior of carbon nanotube filled PTFE composites. Tribol Lett 15: 275-278 (2003)

[16] Zhang L C, Zarudi I, Xiao K Q. Novel behavior of friction 
and wear of epoxy composites reinforced by carbon nanotubes.

Wear 261: 806-811 (2006)

[17] Li C, Chou T W. Elastic moduli of multiwalled carbon nanotubes and the effect of van der Waals forces. Compos Sci Technol 63: 1517-1524 (2003)

[18] Chen W X, Tu J P, Xu Z D, Chen W L, Zhang X B, Cheng D H. Tribological properties of ni-P-multiwalled carbon nanotubes electroless composite coating. Mater Lett 57: 1256-1260 (2003)

[19] Wang C, Xue T, Dong B, Wang Z, Li H L. Polystyreneacrylonitrile-CNTs nanocomposites preparations tribological behavior research. Wear 265: 1923-1926 (2008)

[20] Brown E N, Kessler M R, Sottos N R, White S R. In situ poly(urea-formaldehyde) microencapsulation of dicyclopentadiene. J Microencap 20: 719-730 (2003)

[21] Oliver W C, Pharr G M. An improved technique for determining hardness and elastic modulus using load and displacement sensing indentation experiments. J Mater Res 7: 1564-1583 (1992)

[22] Xiao D S, Rong M Z, Zhang M Q. A novel method for preparing epoxy-containing microcapsules via UV irradiationinduced interfacial copolymerization in emulsions. Polymer 48: 4765-4776 (2007)

[23] Yuan Y C, Rong M Z, Zhang M Q, Chen J, Yang G C, Li X M. Self-healing polymeric materials using epoxy/mercaptan as the healant. Macromolecules 41: 5197-5202 (2008)

[24] Ratna D, Simon G P. Mechanical characterization and morphology of carboxyl randomized poly(2-ethyl hexyl

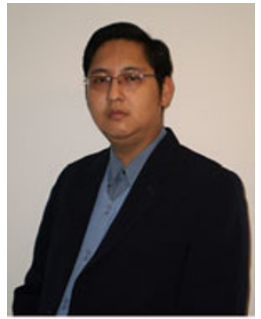

Nay Win KHUN. He received his MS degree in "Mechanics and Processing of Materials" in 2006 and his PhD degree in "Thin Films Physics and Electrochemistry" in 2011, both acrylate) liquid rubber toughened epoxy resins. Polymer 42: 7739-7747 (2001)

[25] Eliezer Z, Schulz C J, Barlow J W. Friction and wear properties of an epoxy-steel system. Wear 46: 397-403 (1978)

[26] Khun N W, Rincon Troconis B C, Frankel G S. Effects of carbon nanotube content on adhesion strength and wear and corrosion resistance of epoxy composite coatings on AA2024-T3. Prog Orga Coat, http://dx.doi.org/10.1016/ j.porgcoat.2013.08.003 (2013)

[27] Archard J F. The temperature of rubbing surfaces. Wear 2: 438-455 (1959)

[28] Ashby M F, Abulawi J, Kong H S. Temperature maps for frictional heating in dry sliding. Tribol Trans 34: 577-587 (1991)

[29] Svahn F, Rudolphi A K, Wallen E. The influence of surface roughness on friction and wear of machine element coatings. Wear 254: 1092-1098 (2003)

[30] Meine K, Schneider T, Spaltmann D, Santner E. The influence of roughness on friction. Part II. The influence of multiple steps. Wear 253: 725-732 (2002)

[31] Tabor D. Surface forces and surface interactions. J Colloid Interface Sci 58: 2-13 (1977)

[32] Xing X S, Li R K Y. Wear behavior of epoxy matrix composites filled with uniform sized sub-micron spherical silica particles. Wear 256: 21-26 (2004)

[33] Durand J M, Vardavoulias M, Jeandin M. Role of reinforcing ceramic particles in the wear behavior of polymer-based model composites. Wear 181-183: 833-850 (1995)

from the Nanyang Technological University, Singapore. His research interests include thin films and coatings, composite materials, corrosion, tribology and surface and interface. 


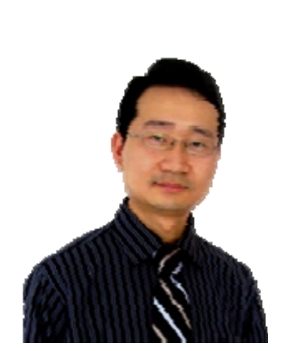

Jinglei YANG. He received his master degree in solid mechanics from the University of Science and Technology of China, and PhD degree from the University of Kaiserslautern, Germany. He joined the School of Mechanical and

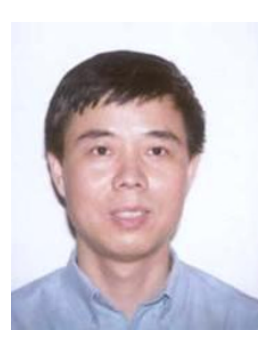

Erjia LIU. He received his bachelor degree in materials engineering from Harbin University of Science \& Technology, master degree in materials engineering from Harbin Institute of Technology, and $\mathrm{PhD}$ degree in metallurgy and materials
Aerospace Engineering at Nanyang Technological University in 2008. His current position is an assistant professor. His research areas cover multifunctional self-healing polymers and coatings, FRP composites and nanocomposites and their mechanical, dynamic, and tribological performances, and encapsulated phase change materials for green building.

engineering from Catholic University of Leuven. He joined the School of Mechanical and Aerospace Engineering at Nanyang Technological University in 1999. His current position is an associate professor. His research interests include thin films and coatings, carbon based materials, nanocomposites, nanotribology, and electrochemistry. 